\title{
Research on the Influencing Factors of the Agricultural Products Purchase Willingness
}

\section{- - Taking Sichuan Changning Dictyophora as an example}

\author{
Zhengjie Zhang $^{1, \text { a }}$ Ju Chang $^{1, b}$ \\ ${ }^{1}$ Sichuan Agricultural University, Chengdu, Sichuan, China, 611830 \\ aemail, ${ }^{\text {bemail, }}$
}

Keywords: Dictyophora, Purchase Willingness, Influencing Factors

\begin{abstract}
The purchase intention is the subjective tendency of the consumer to choose a product and is proved to be an important indicator of the predicted consumption behavior. On the basis of the existing theory of purchase intention, this paper analyzes the influencing factors of the purchase intention of Dictyophora japonica, puts forward the hypothesis, collects the data, uses the Logistic regression model to analyze and verify the hypothesis, and obtain the individual And the family part of the factors, the attitude of consumers and the cognitive factors of Dictyophora, Dictyophora products and market factors, have a significant impact on the purchase price of Dictyophora. Finally, on the basis of data analysis, the relevant suggestions are put forward.
\end{abstract}

\section{Introduction}

Dictyophora has a high variety of edible, medicinal, health care and ornamental values, contains a variety of essential amino acids and rich trace elements, can anti-tumor, antibacterial, anti-aging and enhance immunity; Sun contains natural antibacterial ingredients, with good anti-corrosion function. Dictyophora market price is higher, but with the cultivation of technology, people's health awareness and consumption levels continue to improve, as a natural green health products of bamboo ditch gradually spread to the homes of ordinary people, great economic development. Sichuan Changning County known as "Chinese bamboo town" reputation, has become one of Chinese three major production base of bamboo. With the vigorous development of local tourism and current e-commerce in Changning, and in recent years, the government attaches great importance to the development and sales of agricultural products in the region, giving the industry more policy support, Changning long dress sunrise ushered in a major development opportunities , In the face of opportunity, its own there are many problems. The purchase intention is the subjective tendency of the consumer to choose a product and is proved to be an important indicator of the predicted consumption behavior. The impact of the purchase of the factors are multifaceted, the impact of various factors is different, the current impact of consumer buying factors related to more research, but clear to the purchase of bamboo will affect the impact of factors is still very little. In this paper, we will study the influencing factors of purchase intention in Changning, Sichuan Province as an example, and put forward the hypothesis relationship between the influencing factors and the purchase intention. The logistic regression model is used to analyze the factors.

\section{The Literature Review}

The Meaning of the Purchase Intention. Fishbein (1975) [1] argues that the will is the subjective probability of being engaged in a particular act, the extension of the same concept, the willingness to buy, that is, the willingness of the consumer to take a particular purchase behavior. Garbarino \& Johnson (1999) [2] that the willingness to buy is a kind of willingness, generally refers to the wishes of consumers in the future. Dong Yali (2009) [3] that: consumer desire to buy is a potential reflection of consumer behavior. According to the study of domestic and foreign scholars on the purchase intention, summed up a commonality is: the purchase intention is the consumer within a variety of factors affects the psychological tendencies, and consumer behavior has a more important 
impact.

The Study of the Factors Affecting the Purchase Intention. Kim and Littrell (2001) [4] measured the attitude of tourists using the famous Fishbein model, which proved that visitors' attitudes towards tourist culture would affect their willingness to purchase souvenirs. Zhou et al. (2004) [5] studied the purchase intention of consumers from the point of view of food safety, and thought that the attitude of consumers to food safety would affect their acceptance of food and thus the purchase intention. Sondergaard (1992) [6] By studying the public's willingness to buy enzyme products, it is pointed out that consumers' attitudes towards the formation of the purchase intention of the enzyme products play a preconceived role, and the attitude of identity is easy to produce a positive purchase intention.

Dodds (1991) [7] mentioned in the study whether the consumer is willing to purchase a relative relationship between the price of the product he chooses from the product he wants to buy and the price paid for the product, and that the purchase intention and perception Values are positively correlated, while perceived values are influenced by perceived gains and perceived monetary sacrifices. Zeithaml (1988) [8] from the consumer psychological point of view: consumer awareness of products or services, the higher the benefits of the value of the higher, and high perceived value will increase the consumer's willingness to buy the product The (2003) [9] studied the consumer purchasing decision model based on the customer value, and thought that the perceived value of the customer was influenced by the individual factors such as the psychological and physical factors of the customer and the social, cultural and political factors, especially the individual of the growth and learning experience are closely related, they proposed with the product utility, customer costs, customer needs and customer personality four basic concepts to evaluate the customer's perceived value.

Ajzen (1985) [10] proposed the theory of planned behavior on the basis of rational behavior theory. Since then, a large number of scholars have studied the purchase intention from attitudes, perceived values and subjective norms. Feng Ping (2005) [11] applied the theory of plan behavior to study the consumer's intention to use the Internet banking, the study shows that the impact of consumer Internet banking use of the main factors is the attitude, followed by the perception of behavior control, and subjective norms basically no impact.

Wood \& Scheer (1996) adds the perceived risk and the overall assessment of the purchase to the perceived value model, and considers that perceived risk is one of the costs that must be paid for the product, and perceived gains, monetary costs, and perceived risk Assessment to influence the purchase intention, which perceived risk will directly affect the purchase intention.

The Dictyophora Related Research. For the research of Dictyophora, domestic scholars mainly focus on the cultivation of Dictyophora, its own composition and value, and the development strategy of the whole area of Dictyophora, and from the perspective of consumers to study the demand and development of Dictyophora very few.

The Comments. Through the collating and analysis of the relevant literature, we can see that the research results of the readers' willingness to purchase and the influencing factors are mainly focused on the following two aspects: the first aspect is the connotation of the purchase intention. The second aspect is the influencing factor of the consumer's willingness to buy. From the current consumer willingness to buy and the influencing factors in the empirical analysis of the article can be seen that most of the consumer purchase intention of the study are not clear to the bamboo market, nor from the consumer point of view. In this paper, the logistic regression model is used to analyze the influencing factors of the purchase intention of Dictyophora, and the consumers 'demand and willingness of Dictyophora are considered based on the consumers' perspective. Combining with the advantages of Dictyophora the development of the market strategy of Changning Zhu Sun market and marketing strategy to a certain extent, to enhance its visibility and consumer awareness of the purpose, in this regard can be in-depth study of the Department.

\section{The Theoretical Model and Research Hypothesis}

The Measurement Model. The consumer will buy the product of bamboo sun as the explanatory 
variable y, using Logistic theoretical model, so that y obey the binomial distribution, the consumer will answer the answer with " 1 ", the negative answer with " 0 " said, set $y=1$ probability of $P$, the probability of y specific form:

$$
p=f\left(\beta_{0}+\sum_{i=1}^{n} \beta_{i} X_{i}\right)=\frac{1}{1+\exp -\left(\beta_{0}+\sum_{i=1}^{n} \beta_{i} X_{i}\right)}
$$

Change:

$$
\operatorname{Ln}\left(\frac{p}{1-p}\right)=\beta_{0}+\sum_{i=1}^{n} \beta_{i} X_{i}
$$

The Variable Selection. According to the literature review and the study of the relevant theories, this paper divides the influencing factors of the purchase intention of Dictyophora into three parts (see Table 1).

The first part: the personal and family factors of the consumer, including gender, age, occupation, income level, education level, marital status, family size and family structure and other factors.

The second part: the attitude of consumers and the cognitive factors of Dictyophora, including the degree of understanding of consumers, the degree of love and other factors.

The third part: Dictyophora's product and market factors, including the taste of Dictyophora, nutrition, brand, price, channel, promotion and other factors.

Table 1: the expected effect of each factor on the explanatory variables

Influencing factors

Expected action direction

Personal and family factors

\begin{tabular}{ll}
\hline gender & Uncertain \\
Age & Uncertain \\
The higher the level of education & Positive \\
Marital status is married & Positive \\
Career & Uncertain \\
The larger the family size & Negative \\
There are old people or children in the family & Positive \\
The higher the monthly household income & Positive \\
\hline Attitude and cognitive factors & \\
\hline The higher the degree of understanding & Positive \\
The higher the degree of liking & Positive \\
\hline Product and market factors & Positive \\
\hline Good taste & Positive \\
High nutritional value & Positive \\
Medicinal health is high & Positive \\
The degree of attention to the brand & Positive \\
A high degree of understanding of the brand & Uncertain \\
High price level & Positive \\
High degree of publicity &
\end{tabular}

Make Assumptions. By combining the existing research results and the summary of this paper, the author puts forward three research hypotheses on the influencing factors of consumers' willingness to purchase.

H1: Consumers 'personal and family factors have a significant impact on consumers' willingness to buy Dictyophora.

H2: consumer attitudes and cognitive factors have a significant impact on the willingness of consumers to buy Dictyophora.

H3: Dictyophora's product and market factors have a significant impact on the willingness of consumers to buy Dictyophora.

Data Sources and Processing. According to the three hypotheses proposed in this paper, the 
questionnaire of the thesis is formed by referring to the research basis of scholars. Finally, according to the formation of the questionnaire on the surrounding friends to pre-survey 30, with the information obtained on the questionnaire to further modify and improve the formation of the final questionnaire. According to the final survey questionnaire, 350 questionnaires were collected and 313 were recovered. The recovery rate was $89.43 \%$. Whether the questionnaire was carefully filled, whether the questionnaire was complete, the number of valid samples was 224, and the effective questionnaire rate was $71.57 \%$.

\section{Empirical Results and Analysis}

Descriptive Statistical Analysis. A total of 224 valid samples were obtained. The samples were analyzed from eight perspectives: gender, age, marital status and educational level. Among them, women were more than males, accounting for $52.68 \%$ of males and $47.32 \%$ of males \%; From the age point of view, the age group in the 21-40 age group the majority of the majority, accounting for $61.61 \%$ : followed by the majority of $41-60$ years of age, accounting for $21.43 \%$; unmarried number more than married, respectively Accounting for $52.68 \%$ and $47.32 \%$; the majority of the education level to the university, accounting for $67.85 \%$; occupational distribution more diversified; family size is mainly 3-4 people accounted for 62.5\%; family per capita monthly income of 2000-4000 yuan The main, accounting for $41.96 \%$. In general, the selection of this sample is still relatively reasonable.

In the 224 effective questionnaires, consumers do not understand the palm trees accounted for $3.57 \%$, do not understand accounted for $15.18 \%$, generally accounted for up to $56.25 \%$, understand and understand a total of 25\%, indicating that consumers understand the Dictyophora The degree is still relatively low. Consumers know more about the cooking and eating methods of Dictyophora, and $21.43 \%$ of consumers said they did not understand it at all. Consumers on the understanding of Dictyophora products mainly in the Dictyophora dry goods and Dictyophora wine, Dictyophora related products up to more than 20 kinds of consumer awareness is still relatively low.

Consumers of bamboo dumpling products, the degree of love is relatively high, pay attention to the taste of Dictyophora, nutritional value and medicinal health value, but the value of bamboo roe brand is relatively low, the degree of understanding is relatively low. Consumers of Dictyophora information on the channels are mainly concentrated in: friends and relatives recommended, restaurants, tourism and the Internet several aspects.

Regression Results and Analysis. In this paper, SPSS19.0 statistical software, KMO value of the items and Bartlett spherical degree test, KMO value of 0.786, Bartlett spherical degree test is significant $(\mathrm{P}=0.000)$, approximate card side 3405.296, can be obtained structural efficiency And the sample data were significantly correlated with the research requirements. Cronbach's Alpha value is 0.783 , a coefficient greater than 0.7 , overall reliability is acceptable. The results of H-L test and Omnibus test showed that the chi-square value of H-L test model was 4.121 and the significance level was 0.846 . The original hypothesis could not be rejected and the degree of model fitting was better. The Omnibus test showed that the model was tested at a significance level of 0.01 , indicating that at least one of the independent variables in the model was significantly associated with the dependent variable. Combined with the H-L test and the Omnibus test, the selected model and the regression results can better reflect the consumer's willingness to purchase bamboo.

Whether the purchase of Dictyophora as the dependent variable, sex, age, occupation, family per capita monthly income, education, marital status, family population, whether the elderly or children in the family, the degree of understanding of Dictyophora, The degree of liking, value the taste of Dictyophora, pay attention to the nutritional value of Dictyophora, pay attention to the value of Dictyophora medicinal health care, contact the number of promotional advertising, value bamboo tree product brand, the understanding of the degree of bamboo sun brand, Perceived as independent variables, which occupation is disorderly classification variables, the need to set dummy variables to government agencies or institutions of workers (the first) as a reference category, the Logistic regression analysis: 
Table 2 Logistic regression analysis results

\begin{tabular}{|c|c|c|c|c|c|c|}
\hline & $\mathrm{B}$ & S.E, & Wals & $\mathrm{df}$ & sig. & $\overline{E x p}(\mathrm{~B})$ \\
\hline gender & -0.380 & 0.536 & 0.503 & 1 & 0.478 & 0.684 \\
\hline age & 0.435 & 0.547 & 0.633 & 1 & 0.426 & 0.647 \\
\hline Career & & & 9.235 & 6 & 0.161 & \\
\hline Career (1) & -29.525 & 23848.564 & 0.000 & 1 & 0.999 & 0.000 \\
\hline Career (2) & -26.883 & 23848.564 & 0.000 & 1 & 0.999 & 0.000 \\
\hline Career (3) & -25.450 & 23848.564 & 0.000 & 1 & 0.999 & 0.000 \\
\hline Career (4) & -27.316 & 23848.564 & 0.000 & 1 & 0.999 & 0.000 \\
\hline Career (5) & -22.577 & 23848.564 & 0.000 & 1 & 0.999 & 0.000 \\
\hline Career（6） & -23.739 & 23848.564 & 0.000 & 1 & 0.999 & 0.000 \\
\hline $\begin{array}{l}\text { Family per capita } \\
\text { monthly income }\end{array}$ & 1.441 & 0.289 & 24.862 & 1 & $0.000 * * *$ & 4.225 \\
\hline Education & 0.876 & 0.295 & 8.818 & 1 & $0.009 * * *$ & 2.399 \\
\hline marital status & 1.078 & 1.317 & 0.670 & 1 & 0.413 & 2.940 \\
\hline Family population & 0.514 & 0.524 & 0.963 & 1 & 0.326 & 1.672 \\
\hline Whether there are old peo & ople & & & & & \\
\hline $\begin{array}{l}\text { or children in the family } \\
\text { The degree of understand }\end{array}$ & $\begin{array}{l}0.848 \\
\text { ding }\end{array}$ & 0.640 & 1.758 & 1 & 0.185 & 2.336 \\
\hline of Dictyophora & -1.164 & 0.412 & 7.982 & 1 & $0.012^{* *}$ & 0.312 \\
\hline $\begin{array}{l}\text { The degree of likeness } \\
\text { of Dictyophora }\end{array}$ & -1.361 & 0.343 & 15.744 & 1 & $0.005^{* * *}$ & 0.256 \\
\hline $\begin{array}{l}\text { Look at the taste } \\
\text { of Dictyophora }\end{array}$ & -1.483 & 0.371 & 15.978 & 1 & $0.005^{* * *}$ & 0.227 \\
\hline $\begin{array}{l}\text { Pay attention to the } \\
\text { nutritional value of } \\
\text { Dictyophora }\end{array}$ & -1.352 & 0.451 & 8.987 & 1 & $0.010^{* *}$ & 0.259 \\
\hline $\begin{array}{l}\text { Pay attention to the } \\
\text { medicinal health value }\end{array}$ & & & & & & \\
\hline of Dictyophora & -1.052 & 0.393 & 7.165 & 1 & $0.012^{* *}$ & 0.349 \\
\hline $\begin{array}{l}\text { Number of advertisement } \\
\text { for contact }\end{array}$ & its -0.987 & 0.294 & 11.270 & 1 & $0.008 * * *$ & 0.373 \\
\hline $\begin{array}{l}\text { Look at the brand of } \\
\text { bamboo powder products }\end{array}$ & s $\quad-0.059$ & 0.400 & 0.022 & 1 & 0.882 & 0.943 \\
\hline $\begin{array}{l}\text { The degree of understand } \\
\text { of the brand bamboo } \\
\text { Willing to nav the }\end{array}$ & ding 0.399 & 0.683 & 0.341 & 1 & 0.559 & 1.490 \\
\hline $\begin{array}{l}\text { Willing to pay the } \\
\text { price of Dictyophora }\end{array}$ & 1.023 & 0.257 & 15.845 & 1 & $0.005^{* * *}$ & $\begin{array}{r}2.782 \\
\end{array}$ \\
\hline constant & 13.015 & 23848.564 & 0.000 & 1 & 1.000 & 449219.872 \\
\hline
\end{tabular}

Note: *** represents significant at 0.01 level, ** represents significant at 0.05 level, * represents significant at level 0.1

From the results of Table 2, the independent variable, the family per capita monthly income, education, understanding of the degree of Dictyophora, the degree of bamboo like the sun, the taste of Dictyophora, pay attention to the nutritional value of Dictyophora, Value, the number of contact advertisements, willing to pay the price of Dictyophora has a significant impact on the purchase of Dictyophora.

(Sig. $=0.005$, Wals $=8.818, \mathrm{~B}=0.876)$, willing to pay the price of bamboo moss (sig. $=0.005$, Wals), the average monthly income of the family (sig. $=0.000$, Wals $=24.862, \mathrm{~B}=1.441)=15.845$, $\mathrm{B}=1.023)$ is a positive value, indicating that the higher the monthly income of the family, the higher the degree, the higher the willingness to pay the price of Dictyophora, the higher the willingness of consumers to buy Dictyophora.

(Sig. $=0.012$, Wals $=7.982, \mathrm{~B}=-1.164)$, the degree of darling (sig. $=0.005$, Wals $=15.744, \mathrm{~B}=$ -1.361 ), the taste of Dictyophora ( $($ Sig. $=0.010$, Wals $=8.987, \mathrm{~B}=-1.352$ ), and value the health value of Dictyophora (sig. $=0.012$, Wals $=0.50$, Wals $=15.978, \mathrm{~B}=-1.483$ ) $=7.165, \mathrm{~B}=-1.052$ ), the regression coefficient $(\mathrm{B})$ of the number of advertised advertisements (sig. $=0.008$, Wals $=$ 
11.270, $\mathrm{B}=-0.987$ ) is negative, indicating that the higher the degree of understanding of Dictyophora, Zhoushan's like the higher degree, the more the value of Dictyophora's taste, the more the value of Dictyophora's nutritional value, the more the value of Dictyophora health care, contact the number of advertising more consumers the greater the willingness to buy bamboo.

Sex, age, occupation, marital status, family population, whether the elderly or children in the family and the brand value of bamboo powder products, the understanding of the brand of bamboo sun on the purchase of bamboo did not significantly affect.

Based on the above conclusions and the previous assumptions, the results of the following table 3 are obtained:

Table 3 Suppose the verification results

\begin{tabular}{|c|c|}
\hline Make the assumptions & Analysis conclusion \\
\hline $\begin{array}{l}\text { H1: Consumers 'personal and family factors have a } \\
\text { significant impact on consumers' willingness to buy } \\
\text { Dictyophora }\end{array}$ & Get part of the verification \\
\hline $\begin{array}{l}\text { H2: Consumers 'attitudes and cognitive factors have a } \\
\text { significant impact on consumers' willingness to buy } \\
\text { Dictyophora }\end{array}$ & $\begin{array}{c}\text { Has a significant impact, } \\
\text { get the basic verification }\end{array}$ \\
\hline $\begin{array}{l}\text { H3: The products and market factors of Dictyophora } \\
\text { have a significant effect on the willingness of consumers } \\
\text { to purchase Dictyophora }\end{array}$ & $\begin{array}{c}\text { Has a significant impact, } \\
\text { get the basic verification }\end{array}$ \\
\hline
\end{tabular}

\section{Research Conclusions and Policy Recommendations}

The Conclusions of the Study. In this paper, the factors affecting the purchase intention of Dictyophora japonica were studied by using the Logistic regression model to verify the hypothesis to find out the main factors influencing the consumers' willingness to buy: the individual And the family factors (family per capita monthly income, education); consumer attitudes and cognitive factors (the degree of understanding of the Dictyophora, the degree of Dictyophora); Dictyophora products and market factors (to see the taste of Dictyophora, Pay attention to the nutritional value of Dictyophora, pay attention to the health value of Dictyophora, contact the number of promotional advertising, willing to pay the price of bamboo sun). The higher the monthly income of the family, the higher the academic qualifications, willing to pay the higher the price of bamboo moss, the higher the degree of understanding of the Dictyophora, the higher the degree of bamboo sun like, the more the taste of Dictyophora, the more the value of Dictyophora Nutritional value, the more attention the health value of Dictyophora, contact the number of advertising more consumers the greater the willingness to buy bamboo.

The Policy Recommendations. Strengthen the cultivation and cultivation of Dictyophora technology research and development and enhance the level of industrial science and technology. The traditional bamboo marsh cultivation must be rotated, the location is not fixed, the infrastructure construction and utilization of more difficult, high cost, and thus to speed up technology research and development, to achieve the cultivation of Dictyophora, to overcome the continuous suspension of Dictyophora.

Promote the improvement of the quality inspection system of bamboo trees, the establishment of agricultural product quality, safety supervision and inspection stations, the implementation of the base to quasi-product and product traceability system; bamboo tree leading enterprises and small enterprises into the monitoring range, the development of bamboo sun related norms, Sun quality and safety, put an end to the government-led brand development model of substandard products "free rider" phenomenon.

3) to increase policy support, the development of a wide range of Dictyophora sales channels. At present, Changning Zhu Sun sales of the main channels are: relying on "Shu Nan Zhu Hai" tourism consumer market, sales of Dictyophora tourism products and hotel food sales, accounting for more than $60 \%$ of Changning bamboo sun sales. While maintaining the development of tourism 
consumer market at the same time, Changning Dichen more need is to actively "go out" for the public consumers, so that more people know Dictyophora and its related products.

Strengthen their brand awareness. Changning County is one of Chinese three major production base of Dictyophora, "bamboo sea dress Bamboo Sun" has been certified geographical indications of agricultural products, regional well-known but numerous corporate brand and small visibility, so the company should be in the regional brand to create their own exclusive of the corporate brand. Consumers are currently on the bamboo tree brand perception is still relatively small, companies should seize the opportunity to establish and actively cultivate their own brand awareness and reputation, cultivate customers loyalty to their own brand.

Develop a wide range of Dictyophora products, to establish their own technological advantages. At present, the main products on the market: Dictyophora dry goods, bamboo sun eggs, bamboo sun fine, Dictyophora drink, bamboo sun placenta and other products. In order to compete in the enterprise in an invincible position, we must have their own core competitiveness, bamboo tree enterprises should continue to enhance their research and development capabilities, increase the $\mathrm{R}$ \& D department policy and financial support, but also with agricultural research Institutions and universities to carry out cooperative research and development.

Broaden sales channels, increase publicity efforts. To build the brand and the development of bamboo tree Sun products, need to use a certain media to promote and enhance the visibility. The first step is to pass the enterprise and product information to the consumer, the second step is to attract and maintain the consumer, and the current Zhuxun enterprises in the publicity to do is not enough, bamboo companies to strengthen the bamboo tree products Nutritional value, medicinal health care and other functions of the publicity, as well as Dictyophora cooking methods of publicity, consumers will cook their own, will greatly stimulate the purchase of bamboo products demand. Enterprises should continue to update marketing concepts and means to increase business and consumer information communication, understanding of consumer demand, attention to the network sales platform to build.

Constantly update the planting concept and technology. Changning local Dictyophora has a long history of cultivation, many growers rely on their own accumulated experience to grow, if the growers do not update their own planting ideas and technology, then the production and quality of bamboo dunes will certainly be affected. With the development of scientific research and technology, breaking a lot of Dictyophora planting problems, you can get a higher yield of bamboo, the local government is also actively help farmers continue to improve planting technology.

Achieve direct cooperation with the processing and marketing enterprises docking, access to stable sales channels, reduce market risk; the same time, with the enterprise directly docking and reduce brokers to obtain more revenue.

\section{References}

[1] M Fishbein, I Ajzen. Belief, Attitude, Intention and Behaviour: an introduction to theory and research [J]. Philosophy \& Rhetoric, 1975, 41 (4): 842-844

[2] E Garbarino, MS Johnson. The Different Roles of Satisfaction, Trust, and Commitment in Customer Relationships[J]. Journal of Marketing, 1999, 63 (2): 70-87

[J]. Journal of Business Research, 2009 (8): 202-204 (in Chinese with English abstract) [J]. Journal of Business Research, 2009 (8): 202-204

[4] S Kim, MA Littrell.Souvenir buying intentions for for versus others [J] .Annals of Tourism Research, 2001, 28 (3): 638-657

[5] Zhou Yingheng, Huo Liyue, Peng Xiaojia. Food safety: consumer attitudes, purchase intention and information impact [J]. China Rural Economy, 2004 (11): 53-59

[6] HA Sondergaard, KG Grunert, J Scholderer. Consumer attitudes to enzymes in food production[J]. Trends in Food Science \& Technology, 2005, 16 (10): 466-474

[7] WB Dodds, D Grewal. The Effects of Price, Brand, and Store Information on Buyers' Product Evaluations[J]. Journal of Marketing Research, 1991, 28 (3): 307-319 
[8] LL Berry, A Parasuraman, VA Zeithaml. The service-quality puzzle [J]. Business Horizons, 1988, 31 (5): 35-43

[9] Chen Xinyue, Yang Deli.Customer purchase decision model based on customer value [J]. Management Sciences, 2003, 16 (2): 59-62.

[10] I Ajzen.From Intentions to Action: A Theory of Planned Behavior [J]. Springer verlag, 1985, 11-39

[11] Feng Ping. Consumer network bank willingness to use empirical research[D]. Foreign Economic and Trade University master's degree thesis, 2005

[12] CM Wood, LK Scheer. Incorporating Perceived Risk into Models of Consumer Deal Assessment and Purchase Intent [J]. Advances in Consumer Research, 1996

[13] Xia Xinxin. Genetically modified food consumers to buy the impact of factors[D]. Jinan University master's degree thesis, 2011

[14] Yu Hong. Urban residents edible fungus purchase intention influencing factors [D]. Huazhong Agricultural University master's degree thesis, 2011

[15] Feng Hongbin. Organic agricultural products consumers purchase intention and influencing factors [D]. China Ocean University master's degree thesis, 2013

[16] Feng Jianying, Mu Weisong, Fu Zetian.Study on the Purchaser's Willingness to Buy [J]. Modern Management Science, 2006 (11): 7-9

[17] Xiao Qi. Urban consumer edible fungus purchase behavior research [D]. Huazhong Agricultural University master's degree thesis, 2011

[18] The impact of perceived value of genetically modified food on consumer's willingness to buy [D]. Huazhong Agricultural University Master's Thesis, 2014

[19] $\mathrm{Hu}$ Linna. Analysis of online marketing strategy for agricultural products[J]. Knowledge Economy, 2011 (17): 122-122

[20] Yang Jing, Guo Yaohui, Zheng Lin used to promote the healthy development of bamboo industry in Changning County, Sichuan Province [J]. Edible fungus, 2015, 37 (6): 5-6

[J] .Chinese Journal of Agricultural Science and Technology, 2015 (9): 49-51 (in Chinese with English abstract) "Journal of Agricultural Science and Technology"

[22] Yuan Depei. Zhu Sun's research progress [J]. Journal of Hubei Institute for Nationalities: Medical Sciences, 2006,23 (4): 39-41

[23] ZHANG Bei, HUANG Zhi-ping, WEN Xiao-wei. Marketing stimulus, psychological response and organic vegetable consumers' willingness to buy and behavior - empirical analysis based on ordered Logistic regression model[J]. Agricultural Technology \& Economy, 2014, 02: 47 -56

[24] Mao Yufei, Li Wei.Study on the influencing factors of purchase price of high quality wolfberry in Ningxia based on Logistic model [J]. Journal of Central South University of Forestry, 2015, 06: 134-138.

[25] Li Limin, Wu Lin, Hao Qingsheng.Experimental Study on Consumers' Willingness to Purchase Blueberry Products and Its Influencing Factors [J]. Chines Agricultural Sciences, 2011, 44 (2): 423-431

[26] Zhang Wentong, Dong Wei. SPSS statistical analysis of advanced tutorial[M]. Beijing: Higher Education Press, 2013: 162-180 